\title{
Predictors of perioperative blood loss in total joint arthroplasty.
}

Jai Hyung Park

Rothman Institute of Orthopaedics, Thomas Jefferson University Hospital

Mohammad R Rasouli

Rothman Institute of Orthopaedics, Thomas Jefferson University Hospital

S M Javad Mortazavi

Rothman Institute of Orthopaedics, Thomas Jefferson University Hospital

Anthony T Tokarski

Rothman Institute of Orthopaedics, Thomas Jefferson University Hospital

Mitchell G Maltenfort

Rothman Institute of Orthopaedics, Thomas Jefferson University Hospital

Follow this and additional works at: https://jdc.jefferson.edu/rothman_institute

See next page for additional authors

Part of the Orthopedics Commons

Let us know how access to this document benefits you

\section{Recommended Citation}

Park, Jai Hyung; Rasouli, Mohammad R; Mortazavi, S M Javad; Tokarski, Anthony T; Maltenfort, Mitchell G; and Parvizi, Javad, "Predictors of perioperative blood loss in total joint arthroplasty." (2013). Rothman Institute Faculty Papers. Paper 42.

https://jdc.jefferson.edu/rothman_institute/42

This Article is brought to you for free and open access by the Jefferson Digital Commons. The Jefferson Digital Commons is a service of Thomas Jefferson University's Center for Teaching and Learning (CTL). The Commons is a showcase for Jefferson books and journals, peer-reviewed scholarly publications, unique historical collections from the University archives, and teaching tools. The Jefferson Digital Commons allows researchers and interested readers anywhere in the world to learn about and keep up to date with Jefferson scholarship. This article has been accepted for inclusion in Rothman Institute Faculty Papers by an authorized administrator of the Jefferson Digital Commons. For more information, please contact: JeffersonDigitalCommons@jefferson.edu. 


\section{Authors}

Jai Hyung Park, Mohammad R Rasouli, S M Javad Mortazavi, Anthony T Tokarski, Mitchell G Maltenfort, and Javad Parvizi 


\title{
Predictors of Perioperative Blood Loss in Total Joint Arthroplasty
}

\author{
Jai Hyung Park, MD, PhD, Mohammad R. Rasouli, MD, S.M. Javad Mortazavi, MD, Anthony T. Tokarski, BS, \\ Mitchell G. Maltenfort, PhD, and Javad Parvizi, MD, FRCS \\ Investigation performed at the Rothman Institute of Orthopaedics, Philadelphia, Pennsylvania
}

\begin{abstract}
Background: Despite advances in surgical and anesthetic techniques, lower-extremity total joint arthroplasty is associated with considerable perioperative blood loss. As predictors of perioperative blood loss and allogenic blood transfusion have not yet been well defined, the purpose of this study was to identify clinical predictors for perioperative blood loss and allogenic blood transfusion in patients undergoing total joint arthroplasty.
\end{abstract}

Methods: From 2000 to 2008, all patients undergoing unilateral primary total hip or knee arthroplasty who met the inclusion criteria were enrolled in the study. Perioperative blood loss was calculated with use of a previously validated formula. The predictors of perioperative blood loss and allogenic blood transfusion were identified in a multivariate analysis.

Results: Eleven thousand three hundred and seventy-three patients who underwent total joint arthroplasty, including 4769 patients who underwent total knee arthroplasty and 6604 patients who underwent total hip arthroplasty, were evaluated. Multivariate analysis indicated that an increase in blood loss was associated with being male $(263.59 \mathrm{~mL}$ in male patients who had undergone total hip arthroplasty and $233.60 \mathrm{~mL}$ in male patients who had undergone total knee arthroplasty), a Charlson Comorbidity Index of $>3(293.99 \mathrm{~mL}$ in patients who had undergone total hip arthroplasty and $167.96 \mathrm{~mL}$ in patients who had undergone total knee arthroplasty), and preoperative autologous blood donation (593.51 $\mathrm{mL}$ in patients who had undergone total hip arthroplasty and $592.30 \mathrm{~mL}$ in patients who had undergone total knee arthroplasty). In patients who underwent total hip arthroplasty, regional anesthesia compared with general anesthesia reduced the amount of blood loss. The risk of allogenic blood transfusion increased with the amount of blood loss in the patients who underwent total hip arthroplasty (odds ratio, 1.43 [95\% confidence interval, 1.40 to 1.46]) and the patients who underwent total knee arthroplasty (odds ratio, 1.47 [95\% confidence interval, 1.42 to 1.51]), but the risk of blood transfusion increased with the Charlson Comorbidity Index only in patients who underwent total knee arthroplasty (odds ratio, 3.2 [95\% confidence interval, 1.99 to 5.15]). The risk of allogenic blood transfusion decreased with preoperative autologous blood donation in patients who underwent total hip arthroplasty (odds ratio, 0.01 [95\% confidence interval, 0.01 to 0.02 ]) and patients who underwent total knee arthroplasty (odds ratio, 0.02 [95\% confidence interval, 0.01 to 0.03]).

Conclusions: This study identified some clinical predictors for blood loss in patients undergoing total joint arthroplasty that we believe can be used for implementing more effective blood conservation strategies.

Level of Evidence: Prognostic Level IV. See Instructions for Authors for a complete description of levels of evidence.

$\mathrm{I}$

$\mathrm{n}$ spite of advances in surgical and anesthetic techniques as well as blood conservation strategies, total joint arthroplasty is still associated with substantial blood loss and

many patients need perioperative blood transfusion ${ }^{1,2}$. In addition to issues regarding shortages and $\operatorname{cost}^{3}$, allogenic blood transfusion can be associated with serious complications $s^{4}$.

\footnotetext{
Disclosure: None of the authors received payments or services, either directly or indirectly (i.e., via his or her institution), from a third party in support of any aspect of this work. One or more of the authors, or his or her institution, has had a financial relationship, in the thirty-six months prior to submission of this work, with an entity in the biomedical arena that could be perceived to influence or have the potential to influence what is written in this work. No author has had any other relationships, or has engaged in any other activities, that could be perceived to influence or have the potential to influence what is written in this work. The complete Disclosures of Potential Conflicts of Interest submitted by authors are always provided with the online version of the article.
} 
The Journal of Bone \& Joint Surgery • Jbjs. org Volume 95-A - Number $19 \cdot$ OCtober 2, 2013
Predictors of Perioperative Blood loss

in Total Joint ARThroplasty
Allogenic blood transfusion may prolong the duration of hospital stays $s^{5}$ and may adversely affect the outcomes of surgical patients by increasing the risk of surgical site infection and periprosthetic joint infection ${ }^{6,7}$. Therefore, great effort has been made to reduce the rate of allogenic blood transfusion by implementing various blood conservation strategies to reduce perioperative blood loss ${ }^{4}$.

Identifying patients at increased risk of considerable perioperative blood loss and the need for perioperative blood transfusion is an important step toward establishing an effective blood management strategy ${ }^{8}$. Numerous studies have been performed to identify predictors of transfusion requirement in patients undergoing total joint arthroplasty ${ }^{9-13}$. However, only the role of preoperative hemoglobin as a predictor of transfusion requirement has been well defined ${ }^{12}$. Few studies have elucidated predictors of blood loss during total joint arthroplasty ${ }^{14,15}$, and it is not clear which clinical factors affect perioperative blood loss in patients undergoing total joint arthroplasty. The majority of these studies have their own limitations such as using estimated blood loss and showing a relatively small sample size. Therefore, the present study was designed and was carried out to identify predictors of blood loss as well as the transfusion requirement in a large cohort of patients undergoing total joint arthroplasty with calculated blood loss.

\section{Materials and Methods}

fter obtaining approval from the institutional review board, we retroAspectively reviewed our electronic total joint arthroplasty database to identify patients undergoing primary total joint arthroplasty from January 2000 to December 2008. Patients who underwent simultaneous bilateral total joint arthroplasty or revision surgery and cases with acquired or congenital bleeding disorders were excluded from the study.

Patients' notes were reviewed to obtain required data including demographics, body mass index (BMI), Charlson Comorbidity Index, type of anesthesia, preoperative autologous blood donation, allogenic blood transfusion, and preoperative and postoperative hematocrit and hemoglobin levels.

The Charlson Comorbidity Index is frequently used to assess underlying comorbidities. The Charlson Comorbidity Index was originally designed to determine the risk of ten-year mortality ${ }^{16,17}$. We queried our institutional database with use of codes of the International Classification of Diseases, Ninth Revision, Clinical Modification (ICD-9-CM) to identify comorbidity items, which have previously been described ${ }^{17}$. Raw scores were then adjusted for age.

During the study period, our institution offered preoperative autologous blood donation to all patients who were scheduling for total joint arthroplasty with a hemoglobin level of no less than $11 \mathrm{~g} / \mathrm{dL}$ or a hematocrit level of at least $33 \%$. Autologous blood usually is donated within thirty days preoperatively.

Perioperative blood loss was calculated with use of a previously validated formula as described by Rosencher et al. ${ }^{18}$, in which RBC is the acronym for red blood cells and Hct is the abbreviation for hematocrit:

$$
\begin{aligned}
\text { Total RBC loss }(\mathrm{mL})= & {[\text { Uncompensated RBCloss }(\mathrm{mL})] } \\
& +[\text { Compensated RBC loss }(\mathrm{mL})]
\end{aligned}
$$

$$
\begin{aligned}
\text { Uncompensated RBC loss }(\mathrm{mL})= & {[\operatorname{Initial} \mathrm{RBC}(\mathrm{mL})] } \\
& -[\text { Final RBC }(\mathrm{mL})]
\end{aligned}
$$

Compensated RBCloss $=[$ Sum of RBCs received from the various sources of transfusion]

$$
\begin{gathered}
\text { Initial RBC = }[\text { Estimated blood volume }(\mathrm{mL})] \\
-[\text { Initial Hct level }(\%)] \text { at Day }-1 \\
\text { Final RBC }(\mathrm{mL})=[\text { Estimated blood volume }(\mathrm{mL})] \\
-[\text { Final Hct level }(\%)] \text { at Day }+3
\end{gathered}
$$

The estimated blood volume in milliliters was calculated for women and men separately with use of the formulas:

$$
\begin{gathered}
\text { Women : }\left[\text { Body surface area }\left(\mathrm{m}^{2}\right)\right] \times 2430 \\
\text { Men : }\left[\text { Body surface area }\left(\mathrm{m}^{2}\right)\right] \times 2530
\end{gathered}
$$

where body surface area was calculated as

$$
0.0235 \times[\text { height }(\mathrm{cm})]^{0.42246} \times[\text { weight }(\mathrm{kg})]^{0.51456}
$$

Finally, total blood loss at a hematocrit of $35 \%$ was obtained with use of the following equation:

$$
\text { Total blood loss }(\mathrm{mL})=[\text { Total RBCloss }(\mathrm{mL})] / 0.35
$$

The hemoglobin for patients with preoperative autologous blood donation used for the calculation was drawn after the donation.

\section{Statistical Analysis}

Separate analyses were performed for patients who had undergone total knee arthroplasty and those who had undergone total hip arthroplasty. Multiple linear regression analyses were performed to identify predictors of perioperative hemoglobin drop to control for potential confounders. Multiple regression models were used to identify predictors of perioperative blood loss. Because data on total blood loss were skewed toward lower values, a generalized linear model with a negative binomial family was used to create the models. A linear link function was used so the model would return intercept and parameter estimates that would be additive. All variables were included in the model (sex, age, Charlson Comorbidity Index, BMI, hypertension, diabetes, anemia, preoperative autologous blood donation, type of anesthesia, and preoperative hemoglobin level). BMI, age, and hemoglobin level were included in the model as continuous variables. Also, logistic regression analysis was performed to identify independent predictors of allogenic blood transfusion. The amount of blood loss and the level of hemoglobin drop were also included in the logistic regression analysis in addition to the above-mentioned variables.

We validated the linear and logistic models with use of 200 bootstrap samples for the total knee arthroplasty and total hip arthroplasty groups. With use of this validation method, we used all of the data to generate the models. Each bootstrap was resampled (with replacement) from the original data set, a model was generated, and then the performance of this model against the original data was tested. The correlation coefficient and the mean squared error for linear regression and the area under the curve for the logistic regression models were calculated.

All analyses were done with use of R 2.15.1 (R Foundation for Statistical Computing, Vienna, Austria) using the rms (regression modeling strategies) package for the logistic regression. In this study, we did not provide a priori hypotheses for any particular variable and the analyses were designed as exploratory with a high likelihood of chance findings, so the critical $\mathrm{p}$ value thresholds were adjusted for multiple comparisons. As six multivariate models were created in this study (three models of blood loss, hemoglobin drop, and allogenic blood transfusion for the total hip arthroplasty group and the same three models for the total knee arthroplasty group), using a p value of 0.05 , a Bonferroni-adjusted threshold of 0.0083 was used to assess these models. In each model, an adjusted $\mathrm{p}$ value of 0.05 divided by the number of variables in each model was considered to be significant. 
The Journal of Bone \& Joint Surgery $\cdot$ Jbjs.org Volume 95-A • Number $19 \cdot$ OCtober 2, 2013

Predictors of Perioperative Blood loss

in TOtal Joint ARThroplasty

TABLE I Characteristics of Study Patients

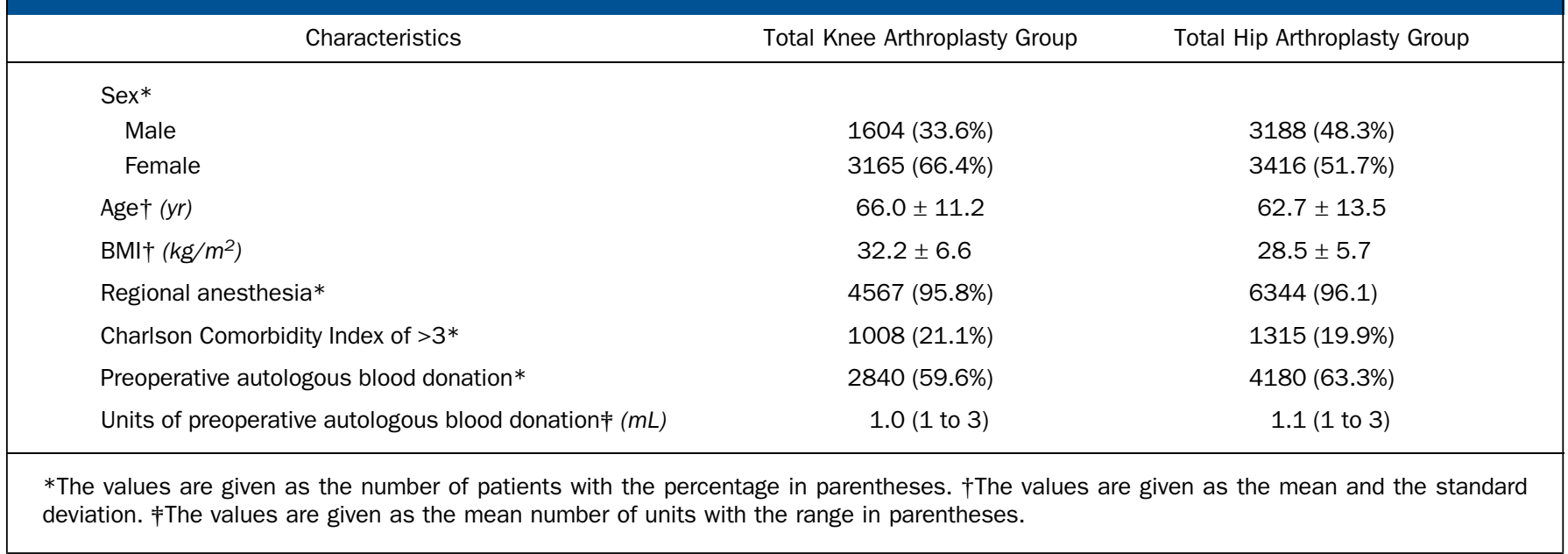

\section{Source of Funding}

No external funds were received for the preparation of this manuscript.

\section{Results}

$\mathrm{C}$ leven thousand three hundred and seventy-three patients E who underwent total joint arthroplasties, including 4769 patients who underwent total knee arthroplasty and 6604 patients who underwent total hip arthroplasty, were evaluated for this study. The mean patient age (and standard deviation) was $66.0 \pm 11.2$ years for those undergoing total knee arthroplasty and $62.7 \pm 13.5$ years for those undergoing total hip arthroplasty. Table I demonstrates the characteristics of the study patients. The most frequent comorbidities in the entire cohort were anemia (36.7\%), hypertension (32.8\%), coronary artery disease $(8.7 \%)$, diabetes mellitus $(7.1 \%)$, and chronic obstructive pulmonary disease $(6.1 \%)$.

\section{Calculated Blood Loss and Hemoglobin Drop}

The mean total calculated blood loss (and standard deviation) was $2181.4 \pm 931.1 \mathrm{~mL}$ for patients undergoing total knee arthroplasty compared with $2363.3 \pm 1124.7 \mathrm{~mL}$ for patients undergoing total hip arthroplasty. Multivariate analysis indicated that the amount of blood loss was increased by male sex (263.59 $\mathrm{mL}$ in patients who underwent total hip arthroplasty and $233.60 \mathrm{~mL}$ in patients who underwent total knee arthroplasty), a Charlson Comorbidity Index of $>3(293.99 \mathrm{~mL}$ in patients who underwent total hip arthroplasty and $167.96 \mathrm{~mL}$ in patients who underwent total knee arthroplasty), and preoperative

TABLE II Results of Multivariate Analysis to Determine Predictors of Blood Loss in Study Patients

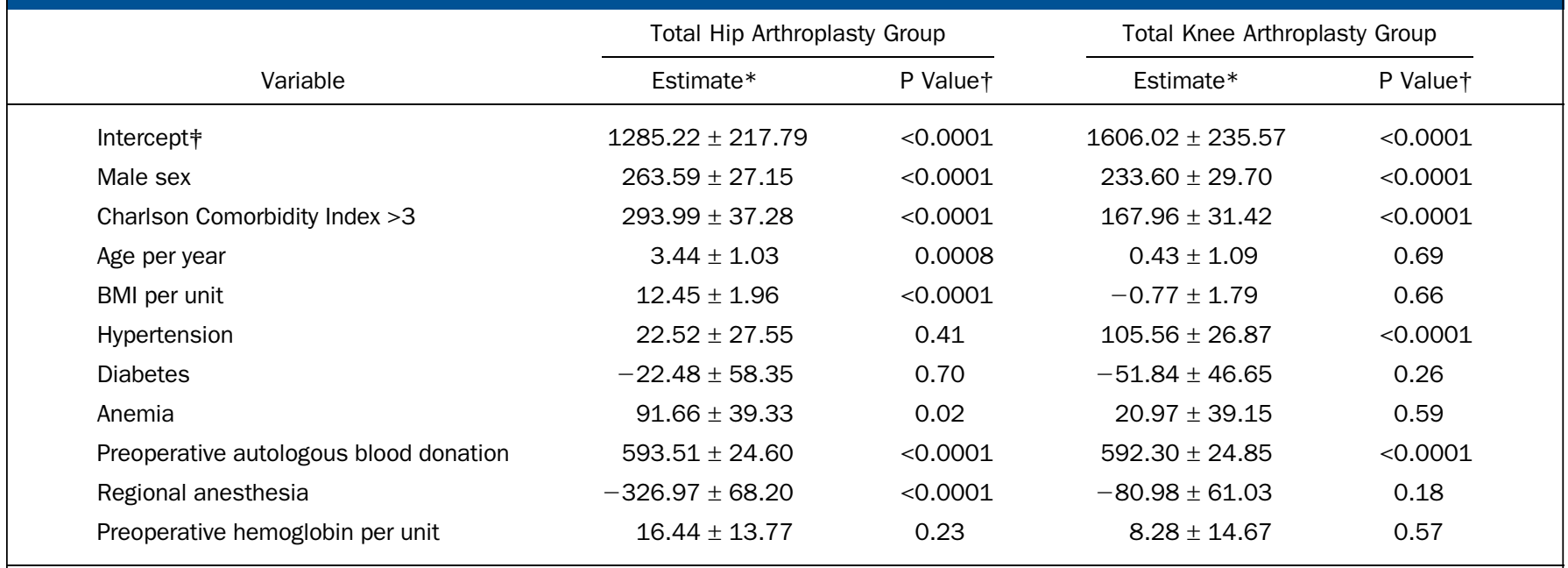

$*$ The values are given as the estimate and the standard error in milliliters. †Significant values were set at $p<0.005$. $\neq$ This category denotes the mean expected estimate without considering other variables. 
TABLE III Multivariate Analysis to Determine Predictors of Hemoglobin Drop in Patients Undergoing Total Joint Arthroplasty

\begin{tabular}{|c|c|c|c|c|}
\hline Variable & \multicolumn{2}{|c|}{ Total Hip Arthroplasty Group } & \multicolumn{2}{|c|}{ Total Knee Arthroplasty Group } \\
\hline Intercept & $-3.84 \pm 0.34$ & $<0.0001$ & $-2.74 \pm 0.32$ & $<0.0001$ \\
\hline Male sex & $-0.09 \pm 0.04$ & 0.02 & $-0.22 \pm 0.04$ & $<0.0001$ \\
\hline Charlson Comorbidity Index of $>3$ & $-0.08 \pm 0.06$ & 0.15 & $0.01 \pm 0.04$ & 0.87 \\
\hline Age per year & $0.00 \pm 0.00$ & 0.77 & $0.00 \pm 0.00$ & 0.03 \\
\hline Hypertension & $-0.07 \pm 0.04$ & 0.12 & $0.05 \pm 0.04$ & 0.14 \\
\hline Diabetes & $0.04 \pm 0.09$ & 0.61 & $-0.04 \pm 0.06$ & 0.55 \\
\hline Anemia & $0.05 \pm 0.06$ & 0.38 & $-0.05 \pm 0.05$ & 0.31 \\
\hline Preoperative autologous blood donation & $-0.18 \pm 0.04$ & $<0.0001$ & $-0.19 \pm 0.03$ & $<0.0001$ \\
\hline Regional anesthesia & $-0.08 \pm 0.09$ & 0.38 & $-0.20 \pm 0.08$ & 0.01 \\
\hline
\end{tabular}

autologous blood donation $(593.51 \mathrm{~mL}$ in patients who underwent total hip arthroplasty and $592.30 \mathrm{~mL}$ in patients who underwent total knee arthroplasty). In patients who have undergone total hip arthroplasty, multivariate analysis also showed that the amount of blood loss rises by increasing age $(3.44 \mathrm{~mL}$ per one-year increase) and BMI $\left(12.45 \mathrm{~mL}\right.$ per $1-\mathrm{kg} / \mathrm{m}^{2}$ increase). In patients undergoing total hip arthroplasty, regional anesthesia compared with general anesthesia reduced the amount of blood loss by $326.97 \mathrm{~mL}$ (Table II). Each model was significant overall $(p<0.0001)$, although the predictive value of both models is poor: the correlation coefficient between prediction and actual observations was 0.12 for patients who underwent total hip arthroplasty and 0.08 for patients who underwent total knee arthroplasty. As each model has ten parameters, a Bonferroni adjustment for multiple comparisons indicates that only $\mathrm{p}$ values of 0.005 should be considered significant within each model.

The mean postoperative hemoglobin drop (and standard deviation) after the surgery was $3.0 \pm 1.2 \mathrm{~g} / \mathrm{dL}$ for patients undergoing total knee arthroplasty and $3.1 \pm 1.6 \mathrm{~g} / \mathrm{dL}$ for patients undergoing total hip arthroplasty. The results of the multivariate analysis of the amount of hemoglobin drop in patients undergoing total hip arthroplasty and patients

TABLE IV Logistic Regression Analysis to Identify Predictors of Allogenic Blood Transfusion in Study Patients

\begin{tabular}{|c|c|c|c|c|}
\hline Variable & \multicolumn{2}{|c|}{ Total Hip Arthroplasty Group } & \multicolumn{2}{|c|}{ Total Knee Arthroplasty Group } \\
\hline Male sex & $0.30(0.22$ to 0.43$)$ & $<0.0001$ & 0.21 (0.12 to 0.37$)$ & $<0.0001$ \\
\hline Charlson Comorbidity Index $>3$ & $1.22(0.81$ to 1.83$)$ & 0.34 & $3.20(1.99$ to 5.15$)$ & $<0.0001$ \\
\hline Age per year & 1.03 (1.02 to 1.05$)$ & 0.0008 & $1.02(1.00$ to 1.04$)$ & 0.88 \\
\hline BMI per unit & 0.91 (0.89 to 0.93$)$ & $<0.0001$ & 0.90 (0.87 to 0.93$)$ & $<0.0001$ \\
\hline Diabetes & 0.96 (0.50 to 1.86$)$ & 0.90 & 0.95 (0.47 to 1.92$)$ & 0.88 \\
\hline Anemia & 1.24 (0.77 to 2.02$)$ & 0.48 & 1.23 (0.61 to 2.48$)$ & 0.56 \\
\hline Preoperative autologous blood donation & 0.01 (0.01 to 0.02$)$ & $<0.0001$ & $0.02(0.01$ to 0.03$)$ & $<0.0001$ \\
\hline Regional anesthesia & $0.78(0.42$ to 1.47$)$ & 0.45 & 2.40 (0.96 to 6.02$)$ & 0.062 \\
\hline Preoperative hemoglobin per unit & 0.65 (0.53 to 0.80$)$ & $<0.0001$ & 0.55 (0.40 to 0.76$)$ & 0.0003 \\
\hline
\end{tabular}


The Journal of Bone \& Joint Surgery - Jbjs.org Volume 95-A - Number $19 \cdot$ OCtober 2, 2013
Predictors of Perioperative Blood Loss in Total Joint ARThroplasty undergoing total knee arthroplasty have been summarized in Table III. Compared with a Bonferroni-adjusted threshold of $\mathrm{p}=0.0083$ for the six multivariate models used in this study, both models are significant $(p<0.0001)$. For the ten explanatory variables within each model, the Bonferroni-adjusted threshold is $\mathrm{p}=0.005$. For the total hip arthroplasty regression, the correlation coefficient is 0.22 and the mean squared error is 2.17; after correcting for optimism (200 bootstrap samples), the correlation coefficient is 0.21 and the mean squared error is still 2.17. For the total knee arthroplasty model, the correlation coefficient is 0.28 and the mean squared error is 1.14; after correction for optimism (200 bootstrap samples), the correlation coefficient is still 0.28 and the mean squared error is 1.15 .

\section{Allogenic Blood Transfusion}

A total number of 698 patients (14.6\%) in the total knee arthroplasty group and 1171 patients $(17.7 \%)$ in the total hip arthroplasty group received allogenic blood transfusion. Logistic regression analysis showed that the risk of allogenic blood transfusion increased with the amount of blood loss in patients who underwent total hip arthroplasty (odds ratio [OR], 1.43 [95\% confidence interval (CI), 1.40 to 1.46]) and patients who underwent total knee arthroplasty (OR, 1.47 [95\% CI, 1.42 to 1.51]) and with the Charlson Comorbidity Index in patients who underwent total knee arthroplasty (OR, 3.2 [95\% CI, 1.99 to 5.15]). Preoperative autologous blood donation decreased the risk of allogenic blood transfusion in patients who underwent total hip arthroplasty (OR, 0.01 [95\% CI, 0.01 to 0.02$]$ ) and patients who underwent total knee arthroplasty (OR, 0.02 [ $95 \%$ CI, 0.01 to 0.03 ]) (Table IV). The predictive power of these models was high; the area under the curve was 0.989 for the total hip arthroplasty model and 0.994 for the total knee arthroplasty model. The correction for optimism with use of 200 bootstrap samples only reduced this performance slightly ( 0.989 for the total hip arthroplasty model and 0.994 for the total knee arthroplasty model). Each model was significant overall $(\mathrm{p}<0.0001)$. The Bonferroni-adjusted threshold for significance for the twelve parameters in each model was $\mathrm{p}=0.004$.

\section{Discussion}

Tn spite of advances in surgical and anesthetic techniques, blood loss during total joint arthroplasty can be substantial ${ }^{2}$. The majority of previous studies regarding blood loss in total joint arthroplasty use estimated blood loss, which does not consider "hidden" blood loss, including loss due to extravasation into the tissues; residual blood in the joint; and loss due to hemolysis, hematoma formation, or bleeding around the prosthesis ${ }^{19}$. The amount of blood loss in total joint arthroplasty can be substantial. Both the total knee arthroplasty and total hip arthroplasty cohorts had $>2 \mathrm{~L}$ of calculated blood loss. The calculated blood loss in our study was relatively close to that in the study by Rosencher et al. ${ }^{18}$. They showed that calculated blood loss was significantly higher $(1944 \mathrm{~mL}$ for patients who underwent total hip arthroplasty and $1934 \mathrm{~mL}$ for patients who underwent total knee arthroplasty) compared with estimates $(750 \mathrm{~mL}$ for patients who underwent total hip arthroplasty and $800 \mathrm{~mL}$ for patients who underwent total knee arthroplasty). Sehat et al. ${ }^{19}$ showed a mean blood loss of $1510 \mathrm{~mL}$ in patients who underwent total hip arthroplasty and $1498 \mathrm{~mL}$ in patients who underwent a total knee arthroplasty and a total blood loss from wound drainage of $74 \%$ in patients who underwent total hip arthroplasty and $51 \%$ in patients who underwent a total knee arthroplasty. The remainder of hidden blood loss was hypothesized to be from considerable bleeding within the soft tissue. In our study, we did not calculate either intraoperative blood loss or hidden blood loss, which is equal to the total blood loss minus the intraoperative and postoperative blood loss. The estimated intraoperative and postoperative blood loss is usually small, consisting of a small proportion of the total blood loss. Although we did not have data on the estimated intraoperative blood loss for patients in our study to compare and to calculate hidden blood loss, considering the large amount of perioperative blood loss in the patients in our study, hidden blood loss was estimated to be large in our patients. As drains are not used routinely at our institution for patients undergoing total joint arthroplasty, we believe that there was considerable bleeding that occurred within the joint and soft tissues postoperatively. The hemoglobin level in our study was also in the range that has been shown in previous studies. The mean hemoglobin drop (and standard deviation) after surgery was $3.0 \pm 1.2 \mathrm{~g} / \mathrm{dL}$ for patients who underwent total knee arthroplasty and $3.1 \pm 1.6 \mathrm{~g} / \mathrm{dL}$ for patients who underwent total hip arthroplasty. The average hemoglobin drop after primary total joint arthroplasty in our study was similar to that in the study by Rosencher et al., which showed a mean hemoglobin drop of $2.8 \mathrm{~g} / \mathrm{dL}^{18}$.

Consistent with previous studies ${ }^{12,20}$, we found that preoperative hemoglobin level is a predictor of allogenic blood transfusion. The present study also showed that preoperative autologous blood donation reduces exposure to allogenic blood in patients undergoing lower-extremity total joint arthroplasty as previously described in some studies on patients undergoing total joint arthroplasty ${ }^{2,21}$. However, it should not be interpreted that preoperative autologous blood donation reduced all sources of blood transfusion or perioperative blood loss. Results of two meta-analyses regarding the effect of preoperative autologous blood donation on the need for blood transfusion showed that preoperative autologous blood donation not only reduces exposure to allogenic blood but also may increase exposure to all red blood cell transfusion in some types of surgical procedures, such as total joint arthroplasty ${ }^{22,23}$. This happens because preoperative autologous blood donation decreases the preoperative hemoglobin level, which is the most important predictor of perioperative blood transfusion. In the present study, preoperative autologous blood donation was paradoxically identified as an independent predictor for blood loss. Although we do not know the exact reason for this finding, similar to our study, Billote and colleagues also found that in patients undergoing total hip arthroplasty, the estimated mean blood 
The Journal of Bone \& Joint Surgery - Jbjs.org Volume 95-A - Number $19 \cdot$ OCtober 2, 2013
Predictors of Perioperative Blood loss

in Total Joint ARThroplasty loss (and standard deviation) was higher in autologous blood donors $(4991 \pm 1042 \mathrm{~mL}$ ) compared with non-donors (4631 $\pm 1108 \mathrm{~mL})^{24}$. They suggested that autologous donors were healthier and larger, which biased the study. In our study, we used multivariate analysis to control for the potential confounders. In this model, preoperative autologous blood donation and the Charlson Comorbidity Index were independently associated with increased blood loss while BMI had a negligible effect on perioperative blood loss. Therefore, the significantly higher blood loss in autologous blood donors in our series cannot be explained by the health status and larger body size of donors. Preoperative autologous blood donation has lost favor in many institutions, given the questions about cost and benefit and the use of tranexamic acid. However, although preoperative autologous blood donation is currently offered less frequently at our institution compared with the study period, it is still offered to patients who are scheduling a total joint arthroplasty. On the basis of our cohort, preoperative autologous blood donation is effective in reducing exposure to allogenic blood.

The health status of patients undergoing total joint arthroplasty, which was evaluated by the use of the American Society of Anesthesiologists (ASA) physical status classification system, is a predictor of blood loss ${ }^{25}$. Grosflam et al. reported that being male, receiving general anesthesia, and having an ASA score of 3 can predict greater total blood loss in patients undergoing total hip arthroplasty ${ }^{25}$. In the present study, we used the Charlson Comorbidity Index as an indicator for comorbidities and found that a Charlson Comorbidity Index of $>3$ is a predictor of blood loss in patients undergoing total knee arthroplasty and patients undergoing total hip arthroplasty. Consistent with previous studies, we showed that perioperative blood loss is greater in male patients ${ }^{25-28}$. In spite of being a predictor of blood loss, male sex was a protective factor against allogenic blood transfusion. Although many factors may contribute to this finding, it could be explained by the higher level of preoperative hemoglobin in male patients compared with female patients as previously reported ${ }^{14}$.

The role of regional anesthesia in reducing blood loss during total joint arthroplasty has been well defined ${ }^{29,30}$. When using spinal anesthesia, the blockade of preganglionic sympathetic nerves affects the vascular smooth muscles and leads to vasodilatation of arterioles, arteries, and veins. A generalized loss of tone of the vascular tree secondary to this sympathetic denervation occurs. As a result, peripheral resistance, especially in the region affected by the spinal anesthesia, decreases. Consequently, blood pressure decreases and the vasomotor paralysis and atony result in bleeding that is slow and can be controlled easily $y^{31,32}$. By considering the role of controlled hypotensive anesthesia in reducing intraoperative blood loss, hypertension may increase blood loss, as was found in this study.

The main limitations of this study related to a lack of data on preoperative medications and the use of other blood conservation strategies other than preoperative autologous blood donation and deep vein thrombosis prophylaxis, which can potentially affect the amount of perioperative blood loss. Although tranexamic acid has routinely been used in our institute in recent years, at the time of this study, it was not in routine use and its potential effect on the study results is negligible. We also do not have data on triggers of blood transfusion in the study patients. Generally, a postoperative hemoglobin level of $8 \mathrm{~g} / \mathrm{dL}$ is considered as a trigger for blood transfusion at our institution. A higher level of hemoglobin may be considered in the presence of hypovolemia symptoms or in patients with underlying cardiac disease. If a patient required blood transfusion, and autologous blood had been collected, autologous blood was typically initially transfused. However, this policy was not followed in all cases.

In conclusion, our study showed that blood loss during total joint arthroplasty is substantial despite using various blood conservation strategies and advances in surgical and anesthetic techniques. Our results showed that although preoperative autologous blood donation reduces exposure to allogenic blood transfusion, it may increase perioperative blood loss. We believe that the results of this study can be used to identify patients who are at an increased risk for large perioperative blood loss and exposure to allogenic blood transfusion during total joint arthroplasty to implement more effective perioperative blood conservation strategies.

Jai Hyung Park, MD, PhD

Mohammad R. Rasouli, MD

S.M. Javad Mortazavi, MD

Anthony T. Tokarski, BS

Mitchell G. Maltenfort, $\mathrm{PhD}$

Javad Parvizi, MD, FRCS

Rothman Institute of Orthopaedics,

Thomas Jefferson University Hospital,

925 Chestnut Street,

Philadelphia, PA 19107.

E-mail address for J. Parvizi: research@rothmaninstitute.com

\section{References}

1. Bierbaum BE, Callaghan JJ, Galante JO, Rubash HE, Tooms RE, Welch RB. An analysis of blood management in patients having a total hip or knee arthroplasty. J Bone Joint Surg Am. 1999 Jan;81(1):2-10.

2. Parvizi J, Chaudhry S, Rasouli MR, Pulido L, Joshi A, Herman JH, Rothman RH. Who needs autologous blood donation in joint replacement? J Knee Surg. 2011 Mar;24(1):25-31.

3. Spiess BD. Blood conservation: why bother? J Cardiothorac Vasc Anesth. 2004 Aug;18(4)(Suppl):1S-5S.

4. Madjdpour C, Heindl V, Spahn DR. Risks, benefits, alternatives and indications of allogenic blood transfusions. Minerva Anestesiol. 2006 May;72(5):283-98.
5. Weber EW, Slappendel R, Prins MH, van der Schaaf DB, Durieux ME, Strümper D. Perioperative blood transfusions and delayed wound healing after hip replacement surgery: effects on duration of hospitalization. Anesth Analg. 2005 May;100(5): 1416-21.

6. Murphy $P$, Heal JM, Blumberg N. Infection or suspected infection after hip replacement surgery with autologous or homologous blood transfusions. Transfusion. 1991 Mar-Apr;31(3):212-7.

7. Pulido L, Ghanem E, Joshi A, Purtill JJ, Parvizi J. Periprosthetic joint infection: the incidence, timing, and predisposing factors. Clin Orthop Relat Res. 2008

Jul;466(7):1710-5. Epub 2008 Apr 18. 
The Journal of Bone \& Joint Surgery · Jbjs.org VOlume 95-A • Number 19 - OCtOBer 2, 2013
Predictors of Perioperative Blood loss

in TOTAL Joint ARThroplasty
8. Keating EM, Meding JB. Perioperative blood management practices in elective orthopaedic surgery. J Am Acad Orthop Surg. 2002 Nov-Dec;10(6):393-400.

9. Guerin S, Collins C, Kapoor H, McClean I, Collins D. Blood transfusion requirement prediction in patients undergoing primary total hip and knee arthroplasty. Transfus Med. 2007 Feb;17(1):37-43.

10. Pola E, Papaleo P, Santoliquido A, Gasparini G, Aulisa L, De Santis E. Clinical factors associated with an increased risk of perioperative blood transfusion in nonanemic patients undergoing total hip arthroplasty. J Bone Joint Surg Am. 2004 Jan;86(1):57-61.

11. Rashiq S, Shah M, Chow AK, $O$ 'Connor PJ, Finegan BA. Predicting allogeneic blood transfusion use in total joint arthroplasty. Anesth Analg. 2004 Oct;99(4):1239-44.

12. Salido JA, Marín LA, Gómez LA, Zorrilla P, Martínez C. Preoperative hemoglobin levels and the need for transfusion after prosthetic hip and knee surgery: analysis of predictive factors. J Bone Joint Surg Am. 2002 Feb;84(2):216-20.

13. Walsh M, Preston C, Bong M, Patel V, Di Cesare PE. Relative risk factors for requirement of blood transfusion after total hip arthroplasty. J Arthroplasty. 2007 Dec;22(8):1162-7. Epub 2007 Apr 20.

14. Bell TH, Berta D, Ralley F, Macdonald SJ, McCalden RW, Bourne RB, Rorabeck $\mathrm{CH}$, Naudie DD. Factors affecting perioperative blood loss and transfusion rates in primary total joint arthroplasty: a prospective analysis of 1642 patients. Can J Surg. 2009 Aug;52(4):295-301.

15. Walker RW, Rosson JR, Bland JM. Blood loss during primary total hip arthroplasty: use of preoperative measurements to predict the need for transfusion. Ann R Coll Surg Engl. 1997 Nov;79(6):438-40.

16. Charlson ME, Pompei $P$, Ales KL, MacKenzie CR. A new method of classifying prognostic comorbidity in longitudinal studies: development and validation. J Chronic Dis. 1987;40(5):373-83.

17. Sundararajan V, Henderson T, Perry C, Muggivan A, Quan H, Ghali WA. New ICD-10 version of the Charlson comorbidity index predicted in-hospital mortality. J Clin Epidemiol. 2004 Dec;57(12):1288-94.

18. Rosencher N, Kerkkamp HE, Macheras G, Munuera LM, Menichella G, Barton DM, Cremers S, Abraham IL; OSTHEO Investigation. Orthopedic Surgery Transfusion Hemoglobin European Overview (OSTHEO) study: blood management in elective knee and hip arthroplasty in Europe. Transfusion. 2003 Apr;43(4):459-69.

19. Sehat KR, Evans R, Newman JH. How much blood is really lost in total knee arthroplasty? Correct blood loss management should take hidden loss into account. Knee. 2000 Jul 1;7(3):151-5.
20. Nuttall GA, Santrach PJ, Oliver WC Jr, Horlocker TT, Shaughnessy WJ, Cabanela $\mathrm{ME}$, Bryant S. The predictors of red cell transfusions in total hip arthroplasties. Transfusion. 1996 Feb;36(2):144-9.

21. Hatzidakis AM, Mendlick RM, McKillip T, Reddy RL, Garvin KL. Preoperative autologous donation for total joint arthroplasty. An analysis of risk factors for allogenic transfusion. J Bone Joint Surg Am. 2000 Jan;82(1):89-100.

22. Forgie MA, Wells PS, Laupacis A, Fergusson D; International Study of Perioperative Transfusion (ISPOT) Investigators. Preoperative autologous donation decreases allogeneic transfusion but increases exposure to all red blood cell transfusion: results of a meta-analysis. Arch Intern Med. 1998 Mar 23;158(6):610-6.

23. Henry DA, Carless PA, Moxey AJ, O'Connell D, Forgie MA, Wells PS, Fergusson D. Pre-operative autologous donation for minimising perioperative allogeneic blood transfusion. Cochrane Database Syst Rev. 2002;(2):CD003602.

24. Billote DB, Glisson SN, Green D, Wixson RL. Efficacy of preoperative autologous blood donation: analysis of blood loss and transfusion practice in total hip replacement. J Clin Anesth. 2000 Nov;12(7):537-42.

25. Grosflam JM, Wright EA, Cleary PD, Katz JN. Predictors of blood loss during total hip replacement surgery. Arthritis Care Res. 1995 Sep;8(3):167-73.

26. Cushner FD, Friedman RJ. Blood loss in total knee arthroplasty. Clin Orthop Relat Res. 1991 Aug;(269):98-101.

27. Prasad N, Padmanabhan V, Mullaji A. Blood loss in total knee arthroplasty: an analysis of risk factors. Int Orthop. 2007 Feb;31(1):39-44. Epub 2006 Mar 28.

28. Churchill WH, McGurk S, Chapman RH, Wallace EL, Bertholf MF, Goodnough LT, Kao KJ, Olson JD, Woodson RD, Surgenor DM. The Collaborative Hospital Transfusion Study: variations in use of autologous blood account for hospital differences in red cell use during primary hip and knee surgery. Transfusion. 1998 Jun;38(6): 530-9.

29. Juelsgaard P, Larsen UT, Sørensen JV, Madsen F, Søballe K. Hypotensive epidural anesthesia in total knee replacement without tourniquet: reduced blood loss and transfusion. Reg Anesth Pain Med. 2001 Mar-Apr;26(2):105-10.

30. Sharrock NE, Salvati EA. Hypotensive epidural anesthesia for total hip arthroplasty: a review. Acta Orthop Scand. 1996 Feb;67(1):91-107.

31. Flordal PA, Neander $G$. Blood loss in total hip replacement. A retrospective study. Arch Orthop Trauma Surg. 1991;111(1):34-8.

32. Sculco TP, Ranawat $C$. The use of spinal anesthesia for total hip-replacement arthroplasty. J Bone Joint Surg Am. 1975 Mar;57(2):173-7.

\section{Update}

The print version of this article has errors that have been corrected in the online version of this article. In the Materials and Methods section, the sentence that reads as "During the study period, our institution offered preoperative autologous blood donation to all patients who were scheduling for total joint arthroplasty with a hemoglobin level of no less than $11 \mathrm{mg} / \mathrm{dL}$ or a hematocrit level of at least 33\%." in the print version now reads as "During the study period, our institution offered preoperative autologous blood donation to all patients who were scheduling for total joint arthroplasty with a hemoglobin level of no less than 11 g/dL or a hematocrit level of at least 33\%." in the online version. In Table III, the footnote that reads as "The values are given as the estimate and the standard error in milligrams per deciliter." in the print version now reads as "The values are given as the estimate and the standard error in grams per deciliter." in the online version. 